\title{
Application of Mobile Learning Platform in Continuing Medical Education
}

\author{
Na Wang ${ }^{1, a}$, Corresponding author: Jinguo Wang ${ }^{2, b}$ \\ ${ }^{1}$ Department of Anesthesiology, The First Hospital of Jilin University, Changchun, 130021, China \\ ${ }^{2}$ Department of Urology, The First Hospital of Jilin University, Changchun, 130021, China \\ aemail: wangna080613@163.com, bemail: wangjinguolily@163.com
}

\section{Keywords: Application; Mobile Learning Platform; Continuing Education; Medical Education}

\begin{abstract}
Mobile learning has outstanding characteristics including situational correlation, real-time and interaction, so it is suitable for continuing medical education. On the base of current status of mobile learning and information teaching in medical continuing education, we analyze the necessity of mobile learning and how to construct mobile learning platform and promote the application of mobile learning in medical continuing education on the aspects of building mobile learning platform, the development of mobile learning resources and the selection of mobile terminal aspects.
\end{abstract}

\section{Introduction}

The communication enterprises have begun to get into the field of the mobile learning with its sharp insights of market. Mobile learning refers to learning based on the Internet and mobile devices, and the more specific definition of mobile learning is that mobile learning is a kind of education and learning which can occur at any time and any place. Mobile learning is based on the use of mobile computing devices which must effectively present learning content and provide a mutual communication between teachers and students.

Some domestic research units carried out researches about mobile learning. But overall, the research is still in its infancy, yet it is not as a real education mode to promote in the university. Nowadays network education training companies have firstly got in the mobile market and promoted the development of this new industry and applied the research achievement into use [1].

\section{The characteristics of the continuing medical education}

Continuing medical education originated in the United States. Basic education is the focus in medical colleges and universities, and then a lifetime medicine education system after graduation includes learning the new theory, new knowledge, new technology and new method. This education system can make health providers learn throughout their career, keep the noble professional ethics, constantly improve the professional ability and business level and improve the quality of service, so as to adapt to the development of medical science and society. With the development of modern medical science, how to conduct continuing education is an urgent problem.

At present the main means is low click type and the lever type, low click type is on the bottom of the ball through attack the ball flew over obstacles, this method is able to pick the ball's advantages and makes the energy loss in institutions least, the shortcoming is the ball high requirement of the shape of the electromagnetic valve [2].

The developed countries have some useful experiences. Continuing medical education system in the developed countries have mainly two types: one kind is mandatory for continuing medical education system which was mainly established by legislation. France and the United States are in these countries [3]. The other kind is the continuing medical education system which relies on medical personnel to learn actively, because of the absence of hard rules for continuing medical education. The representative countries are UK and Japan. 


\section{The advantages of mobile learning}

The mobile learning is necessary for medical education because of its outstanding characteristics including relevance, autonomy and real-time interaction. Its application in the continuing medical education makes clinical doctors and teachers reach the knowledge they needed at any place and effectively track the patient's treatment process and learn the training process of cattle. Help continue education of clinical doctors in clinical work, greatly improving the clinical effect of learning. Using a mobile phone on a remote server related data, to deal with the difficulties encountered in the actual work, take a good practical effect.

It is important how to design for mobile learning practical courses which is suitable for learning at any time and any place. It is suitable for mobile devices, become the first need to solve the problem. Informal learning is a kind of self teaching and learning positively. It is the result of direct interaction and abundant hint information from partners and teacher, information far beyond the explicit content, students in college or a lot of knowledge and skills from fellow students learn, rather than learned from class or a professor. Mobile terminal for learning content short, adult learners have a real purpose to solve the problem is the provider's lifelong learning curriculum design must satisfy the two characteristics of mobile learning [4].

\section{The construction of mobile medical teaching platform}

In the clinical practice in the real situation, interns can use handheld mobile devices record of clinical practice in the patient's medical records and information, database connection medical center, always consult and follow-up treatment, auxiliary solve the problem of clinical medicine, such as rapid access to the doctor's advice, regimen, drug interactions and adverse reactions, through the relevant data, query on a remote server to make a correct diagnosis of the disease. These features can help clinical doctors to consolidate knowledge, improve the effect of learning. At the same time, teaching the doctor also can through this platform to understand the learning process and the effect of clinical doctors, educational administration departments can also track the clinical doctor's internship at any time [5].

Network and the existing hospital management information system are the base of mobile learning in the hospital. It includes hospitals, the classroom, the teacher's office, a library, a doctor's office, the nurse station. Even in the wards, clinicians can get access to learning resources at any time, upload study notes and take test, online participate in discussions and answer questions. Teachers can use this platform release their teaching plan, electronic lesson plans, multimedia courseware, and homework assignments can also use this platform to clinical doctors communicate more freedom, so as to promote its effective autonomous learning, inquiry learning and collaborative learning, and to evaluate the effect of learning. The traditional teaching and network teaching to the mobile terminal environment migration, construction into a set of teaching organization, resource distribution, teaching management and teaching service is a body comprehensive information platform [6].

\section{The development and management of mobile learning resources}

Network cable network and wireless network can be used, however, due to a large number of wireless communications equipment deployment in the hospital, may affect the normal operation of the medical instruments and equipment, so you can adopt the way of combination of wired and wireless, set different networks in different area. In mobile core teaching platform is a comprehensive medical information center, including clinical medical data center, to the dormitory, classroom building, library, hospital each department, even the field training hospital connected into a network, a large number of layout network port in these areas.

Clinical doctors in different stages of the whole process of learning to update learning materials, download and finish the homework after submit, for the teachers [7]. In addition, still should be developed in view of the continuing education of the teaching content, in order to meet the needs of 
the on-the-job personnel for training. In order to ensure the safety of teaching content, should formulate strict and resource management system, monitoring site content published resources, establish access classification mechanism, teachers need a password to get access to the design of teaching resources, and all editing actions need to be approved by the corresponding subject administrator, in order to ensure that the content of security. The teaching platform not only provides the online course, it is unique in the course content

The health providers can use the system at any time and at any place. Clinical doctors can download professional training courses from the website to the portable digital devices, and then study according to their schedule at any time.

\section{The choice of mobile learning products}

With the improvement of mobile computing technology, the hardware devices of mobile learning are good enough to reach a practical level. Mobile learning devices should have portability and mobility, namely equipment small shape, light weight, easy to carry, can also be very good use in the mobile. Medical education applications have special requirements on the performance of mobile devices, for example, you can play audio, video, ability of digital computing, browse the medical digital image, editor of medical records, medical data query can be connected to the wired and wireless network, and so on function, which requires the mobile terminal has the strong ability of operation, high enough screen resolution and the display size, input is convenient, reliable performance, and is easy to disinfect. It have designed for the doctor to develop a kind of can put a clause in his coat pocket portable devices is also a good choice [8]. Combination all kinds of mobile computing devices and mobile education, it will appear more suitable mobile devices and services.

Our country is a large country and has many doctors in remote areas, so it is difficult to provide them with continuing education. Combining education resources and mobile learning platform is an effective for them to study. Through this platform, the clinical doctors can become lifelong learners in medical schools in the distant workplace, download education resources and get continuing education [9]. At the same time, from the economic point of view, the remote education mode can also save the on-the-job personnel somewhere on learning and it takes a lot of time and money.

The ministry of industry and information technology claimed our country officially entered $4 \mathrm{G}$ period, because Chinese three major telecommunication companies issued the fourth generation mobile communication, marked. $4 \mathrm{~g}$ network powerful images, music, video and other media processing power is bound to be used widely in the field of mobile learning. As a medical education workers, should follow closely the development of modern information technology, combined with the actual situation of mobile learning actively exploration and practice in medical education, to promote medical education to make due contributions to the modernization.

\section{Conclusion}

Clinicians hope to continue education activities way more is given priority to with amateur, different levels of clinical doctors hope to participate in continuing education activities in different ways. The factors influence clinical physicians to participate in continuing education activities more, several factors before is not enough time, learning cost, and traffic inconvenience. The popularity of mobile learning platform can fully understand the health demand, targeted to carry out continuing medical education activities, make the continuing medical education play a more important role in medical treatment activity of physician.

\section{References}

[1] Chenting Su, M. Joseph Sirgy, James E. Littlefield. Is Guanxi Orientation Bad, Ethically Speaking? A Study of Chinese Enterprises[J]. Journal of Business Ethics. 2003 (4)

[2] Pang-Ning Tan, Vipin Kumar. Discovery of Web Robot Sessions Based on their Navigational 
Patterns[J]. Data Mining and Knowledge Discovery. 2002 (1)

[3] Bamshad Mobasher, Honghua Dai, Tao Luo, Miki Nakagawa. Discovery and Evaluation of Aggregate Usage Profiles for Web Personalization[J]. Data Mining and Knowledge Discovery. $2002(1)$

[4] Edward Hartono, Clyde Holsapple. Theoretical foundations for collaborative commerce research and practice[J]. Information Systems and e-Business Management. 2004 (1)

[5] Greg Ogrinc, Linda A. Headrick, Laura J. Morrison, Tina Foster. Teaching and assessing resident competence in practice-based learning and improvement[J]. Journal of General Internal Medicine. 2004 (5)

[6] Feng Wang, Michael J. Hannafin. Design-based research and technology-enhanced learning environments[J]. Educational Technology Research and Development. 2005 (4)

[7] Douglas R. White, Jason Owen-Smith, James Moody, Walter W. Powell. Networks, Fields and Organizations: Micro-Dynamics, Scale and Cohesive Embeddings[J]. Computational \& Mathematical Organization Theory. 2004 (1)

[8] JA Clark, A Tsiaparas. Bandwidth-On-Demand Networks-A Solution to Peer-To-Peer File Sharing[J]. BT Technology Journal. 2002 (1)

[9] Roberta L. Slavin. Operative Group Dynamics in School Settings: Structuring to Enhance Educational, Social, and Emotional Progress[J]. Group. 2002 (4) 